\title{
The impact of energy consumption on Carbon Intensity of Human Well-Being (CIWB)
}

\author{
Nguyen Thuan ${ }^{1}$, Dang Bac Hai ${ }^{1,2 *}$ \\ ${ }^{1}$ Ho Chi Minh City Open University, Vietnam \\ ${ }^{2}$ University of Natural Resources and Environment, Vietnam \\ *Corresponding author: haidb.16ae@ou.edu.vn
}

\begin{abstract}
ARTICLE INFO
ABSTRACT

DOI: $10.46223 /$ HCMCOUJS. econ.en.11.1.1360.2021

Received: December $22^{\text {nd }}, 2020$

Revised: January $27^{\text {th }}, 2021$

Accepted: January $28^{\text {th }}, 2021$

Keywords:

CIWB, energy consumption, FDI, GDP, two-way fixed effects regression

A key concern when constructing sustainable development policy is reducing the negative impact on environmental systems and maximizing human welfare. In this study, we assess how energy consumption effected on Carbon intensity of human wellbeing (CIWB). Using two-way fixed effects in panel regression, this relationship has been investigated during 2000-2018 for 9 lower middle-income countries including Algeria, Bangladesh, Egypt, India, Morocco, Pakistan, Philippines, Uzbekistan and Vietnam, while adding GDP and FDI per capita as control variables. The study reveals that the use of energy for economic development is ineffective and inconsistent with the overview of sustainable development due to the result of increasing CIWB. However, the sign of negative coefficients of GDP and FDI per capita in control variables have given the striking findings that these factors will be helpful for lower middle - income countries to pursue sustainable development by reducing CIWB.
\end{abstract}

\section{Introduction}

An assessment of the nexus between economic activity and environmental stressors offers important policy implications. This could help policymakers move towards economic sustainability in the future (Bretschger \& Smulders, 2007; Narayan \& Narayan, 2010). The term 'sustainability' refers to the standard behavior with respect to the way humans should act towards the environment, and how they are responsible towards one another and generations to come. Baumgartner and Quaas (2010a,b) and Becker (2012) consider that sustainability economics combines two central concepts: justice (from sustainability) and efficiency (from economics). Recently, a new research direction has emerged that evaluates the relationship between various forms of socioeconomic development and what is known as the carbon intensity of well-being (CIWB) Jorgenson and Givens (2015) measured as a ratio of carbon dioxide emissions/life expectancy at birth ${ }^{1}$. These studies aim to analyze the extent to which socioeconomic development increases human well-being in countries and reduces anthropogenic contributions to the environment.

Energy plays an important role in economic development and human life. At the same

\footnotetext{
${ }^{1}$ According to Dietz et al. (2012) suggested that life expectancy at birth, is generally understood to be a good measure of human well-being (although it is by no means perfect).It is a direct indicator of health and longevity. It captures the overall health conditions of society since it directly reflects longer life-spans and reductions in infant mortality, and indirectly reflects pre-natal education, life-long medical services, and levels of literacy and education.
} 
time, the mechanism of development and human life, the use of fossil energy will create threats to the environment and negatively affect human well-being. However, very few studies have mentioned the relationship between energy consumption and CIWB. Of the existing studies exploring this relationship, it was noted that a potentially complicated factor in the assessments regarding the correlation between energy consumption and CIWB is the change in the energy use policies in the countries. Therefore, in order to consider whether the energy consumption policy is geared towards economic sustainability, this article will study the impact of energy consumption on the CIWB. If energy consumption leads to reductions in CIWB, the energy consumption policy will have a positive impact on improving sustainability. If energy consumption increases $\mathrm{CIWB}$, it is necessary to promulgate more relevant policies to reduce these undesirable environmental impacts.

\section{Literature review}

\subsection{Theoretical background}

The Treadmill of Production Theory (TPT) states that environmental degradation and pollution are an inherent part of the development process (Schnaiberg, 1980; Schnaiberg \& Gould, 1994). Given that the capitalist economy is predicated on the constant pursuit of expansion and continuous production due to the profit motive of the producers increases energy use and carbon emission, thereby having a negative effect on the welfare. This is worse when manufacturers apply new production technology that requires a heavy reliance on energy use and more carbon emission. In this regard, although per capita income may increase after increased energy use, it will worsen the well-being of people not only by increasing carbon emissions but also by making energy less accessible to them (Gould, Pellow, \& Schnaiberg, 2004). As a result, Lewis (2019) applied the Treadmill of Production's social change model to explain the case of Ecuador's changing development trajectory from the 1970s to 2017. Using a Panel Study of the Ecological Footprints of Nations, 1975-2000, Jorgenson and Clark (2009) indicated that the treadmill of production in the context of economic development increases per capita footprints and the treadmill of destruction in the mode of military expenditures per soldier positively affects per capita footprints.

\subsection{Empirical literature}

\subsubsection{The relationship between energy consumption and environmental pollution}

The relationship between energy consumption and environmental emissions is divided into two investigative directions in country-specific literature and multi-country studies (Adewuyi \& Awodumi, 2017; Alkhathlan \& Javid, 2015; Ang, 2008; Saidi \& Mbarek, 2016; Tiba \& Omri, 2017). Although, a general conclusion from these studies is that contradictory results, most generally confirm that energy consumption is a key source of environmental emissions (carbon emissions) through direct and indirect channels.

Studies in individual country such as France, Ang (2007) suggest that increasing energy consumption will lead to an increase in carbon emissions. In the case of Turkey, Halicioglu (2009) found only energy consumption has a relationship with $\mathrm{CO} 2$ emissions in the long run. Similar results were found in China as reported by Zhang and Cheng (2009); Ang (2008) in Malaysia; Shahbaz, Lean, and Shabbir (2012) in Pakistan and by Kanjilal and Ghosh (2013) in India.

On the other hand, research by Apergis and Payne (2009) in six Central American countries shows that there is a one-way relationship from energy consumption to $\mathrm{CO} 2$ emissions. Saboori and Sulaiman (2013) studied in five ASEAN countries and found evidence of a two-way 
relationship between energy consumption and $\mathrm{CO} 2$ emissions in these countries. This also means that $\mathrm{CO} 2$ emissions and energy consumption are highly correlated. Cowan, Chang, Inglesi-Lotz, and Gupta (2014) studied in the BRICS countries found mixed results for this relationship. In India, electricity consumption is the cause of $\mathrm{CO} 2$ emissions, while Russia, China, Brazil and South Africa have not found a causal relationship between electricity consumption and CO2 emissions. Chen, Chen, Hsu, and Chen (2016) investigated the relationship between energy consumption and $\mathrm{CO} 2$ emissions in 188 countries, the authors confirm a one-way relationship from energy consumption to $\mathrm{CO} 2$ emissions for both developed and developing country group. Dogan and Aslan (2017) argue that there is a two-way relationship between energy consumption and $\mathrm{CO} 2$ emissions in European countries.

\subsubsection{The relationship between energy consumption and well-being}

Several previous studies have examined the link between indicators of living standard and energy consumption (Martínez \& Ebenhack, 2008; Mazur \& Rosa, 1974; Pasternak, 2001; Suarez, 1995) Most studies have found a strong relationship between energy and living standard at lower energy consumption levels (developing countries) and constant at higher energy consumption levels (developed countries). The standard of living that did not increase at high levels of energy consumption was referred to as the "plateau" by Pasternak (2001) or the "saturation" by Martínez and Ebenhack (2008). In the study of Mazur and Rosa (1974), they concluded their study of 55 countries by describing this model and stating that "so long as America's per capita energy consumption does not go below that of other developed nations, we can sustain a reduction in energy use without long-term deterioration of our [non-economic] indicators." In contrast, Suarez (1995) compared the energy and HDI index in the period 196065 with the period 1991-1992 and found an average improvement in HDI at lower energy levels in the later data set.

\section{Data and methods}

\subsection{Model and data}

This study collects panel data covering the period 2000-2018 for 9 lower middle-income group (Algeria, Bangladesh, Egypt, India, Morocco, Pakistan, Philippines, Uzbekistan and Vietnam). Thus, our data sample includes 171 observations. Data sources were collected from the information of Worldbank, UCSTAD, countryeconomy, ourworldindata. In which, the data per capita income (GDP) measures the level of development is calculated in thousand USD at constant prices in 2010 and LE (average life expectancy) is measured by the number of years taken from Worldbank, foreign investment per capita (FDI) is measured in USD from UCSTAD, carbon dioxide emissions per capita (CO2) measured in tons from Countryeconomy ${ }^{2}$ and energy consumption per capita (EPC) in thousand Kwh from Ourworldindata ${ }^{3}$.

Basing on TPT theory, CIWB $_{\text {it }}$ is a function of the following economic performance variables:

$$
\mathrm{CIWB}_{\mathrm{it}}=\mathrm{F}\left(\mathrm{EPC}_{\mathrm{it}}, \mathrm{GDP}_{\mathrm{it}}, \mathrm{FDI}_{\mathrm{it}}\right)
$$

We assume equation (1) is a linear equation. The selected variables are based on not only TPT but also previous empirical studies on $\mathrm{CO} 2$ emissions and human well-being. The subscript $i$ denotes the unit of our analysis, i.e., country. Subscript t represents the time. CIWB $B_{\text {it }}$ denotes territorial CIWB, $\mathrm{Y}_{\text {it }}$ is the GDP per capita, $\mathrm{EPC}_{\mathrm{it}}$ is energy consumption per capita and $\mathrm{FDI}_{\text {it }}$ is foreign investment per capita. Technically, our goal is to consider the impact of $\mathrm{EPC}_{\mathrm{it}} \mathrm{CIW}_{\mathrm{CW}} \mathrm{B}_{\mathrm{it}}$,

\footnotetext{
${ }^{2} \mathrm{https}: / /$ countryeconomy.com
}

${ }^{3}$ https://ourworldindata.org 
the variables $\mathrm{GDP}_{\text {it }}$ and $\mathrm{FDI}_{\mathrm{it}}$ serve as a control variable. The method for estimating equation (1), which is a two-way fixed-effect technique, concentrates on two simultaneous tasks: explaining the outcomes within-country variation, and reducing the likelihood of biased model estimates resulting from similar However, to make the estimation results more reasonable, we need to add two control variables that change over time.

\subsection{Methodology}

The study applied the time-series cross-sectional Prais-Winsten regression model with panel-corrected standard errors (PCSE). This methodology has been recommended by Beck and Katz (1995) because the feasible generalized least squares (FGLS) method produces incorrect standard errors. However, Cameron and Trivedi (2010) suggested that disturbances are heteroskedastic and contemporaneously correlated across panels. This paper collects data over a 19-year period for 9 low-income countries in the middle-income group, so the authors corrected for first-order autocorrelation (AR1) within panels. We estimated our model by the two-way fixed effect technique. We control for both period-specific and unit-specific disturbances. Our general model is as follows:

$$
\mathrm{Y}_{\mathrm{it}}=\theta \mathrm{X}_{\mathrm{it}}+\mathrm{u}_{\mathrm{i}}+\varepsilon_{\mathrm{t}}+\mathrm{e}_{\mathrm{it}}
$$

Where $Y_{i t}$ denotes the dependent variable for each country at each time period, $\theta \mathrm{X}_{\mathrm{it}}$ represents the vector of coefficients for explanatory variables for each country that vary over time, $u_{i}$ is the unit-specific (i.e., country-specific) disturbance term, $\varepsilon_{t}$ is the period-specific disturbance term that is constant across all countries, and $e_{i t}$ is the disturbance term unique to each country at each point in time. Throughout our empirical estimations, we use dummy variables to control for country-specific disturbances $\left(u_{i}\right)$ and time-specific disturbances (et). The former controls for potential unobserved characteristics that is temporally invariant within countries (unit specific intercepts), while the latter act as controls for any unobserved features that is cross-sectionally invariant within periods (period-specific intercepts). More precisely, the two-way fixed-effect method focuses on two instantaneous missions: (i) clarifying the results within-country variation, and (ii) dropping the probability of biased model estimates arising from similar time trends.

The two-way fixed-effect technique of our paper has the following form:

$$
\begin{aligned}
& \mathrm{CIWB}_{\mathrm{it}}=\theta_{1} \mathrm{ECP}_{\mathrm{it}}+\theta_{2} \mathrm{ECP}_{\mathrm{it}}{ }^{*} \text { year2001 } \ldots . . .+\theta_{18} \mathrm{ECP}_{\mathrm{it}}{ }^{*} \text { year2018 }+\theta_{19} \text { year } 2001+\ldots+ \\
& \theta_{37} \text { year } 2018+\theta_{38} \mathrm{GDP}_{\mathrm{it}}+\theta_{39} \mathrm{FDI}_{\mathrm{it}}+\mathrm{u}_{\mathrm{i}}+\mathrm{e}_{\mathrm{it}}
\end{aligned}
$$

where $\mathrm{CIWB}_{\mathrm{it}}$, the dependent variable, is the carbon intensity of wellbeing, and the model includes ECP per capita $\left(\theta_{1} \mathrm{ECP}_{\mathrm{it}}\right)$, the interaction for ECP per capita and the dummy variables for each year $\left(\theta_{2} \mathrm{ECP}_{\mathrm{it}}{ }^{*}\right.$ year2001+...+ $\theta_{18} \mathrm{ECP}_{\mathrm{it}}{ }^{*}$ year2018), where 2000 is the reference

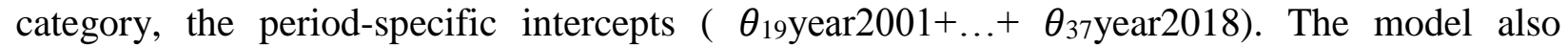
includes the gross domestic product per capita $\left(\theta_{38} \mathrm{GDP}_{i t}\right)$, foreign investment per capita $\left(\theta_{39} \mathrm{FDI}_{\mathrm{it}}\right)$, the country-specific intercepts $\left(\mathrm{u}_{\mathrm{i}}\right)$ and the disturbance term unique to each country at each point in time $\left(\mathrm{e}_{\mathrm{i}}\right)$. The estimated parameter of ECP $\left(\theta_{1}\right)$ per capita is the unit change in the dependent variable $\left(\mathrm{CIWB}_{\mathrm{it}}\right)$ in 2000 for each unit increase in ECP per capita for the same year. The overall effect of ECP per capita subsequent years (e.g., 2001, 2002, .., 2017,2018) equals the sum of the coefficient for ECP per capita (i.e., its effect in 2000) and the appropriate interaction term if the latter is statistically significant (Allison, 2009).

\section{Results}

Descriptive statistics for all variables included can be found in Table 1 and Figure 1 
below. According to Kline (2015) variables with skewness $> \pm 3$ and kurtosis $> \pm 10$, the data have problems with the normal distribution. The distribution of skewness and kurtosis for all the variables were within the acceptable ranges, we do not need to convert the data by using the natural logarithm.

Table 1

Descriptive statistics

\begin{tabular}{|l|c|c|c|c|}
\hline \multicolumn{1}{|c|}{ STats } & CIWB & FDI & GDP & ECP \\
\hline Mean & 34.09786 & 38.22542 & 1.961481 & 7.5651 \\
Sd & 1,874719 & 36.17273 & 1.11325 & 5.453634 \\
Skewness & 0.8131247 & 1.157005 & 0.9799913 & 1.217838 \\
Kurtosis & 3.910398 & 3.730798 & 3.208365 & 3.725438 \\
\hline
\end{tabular}

Source: The reseacher's data analysis

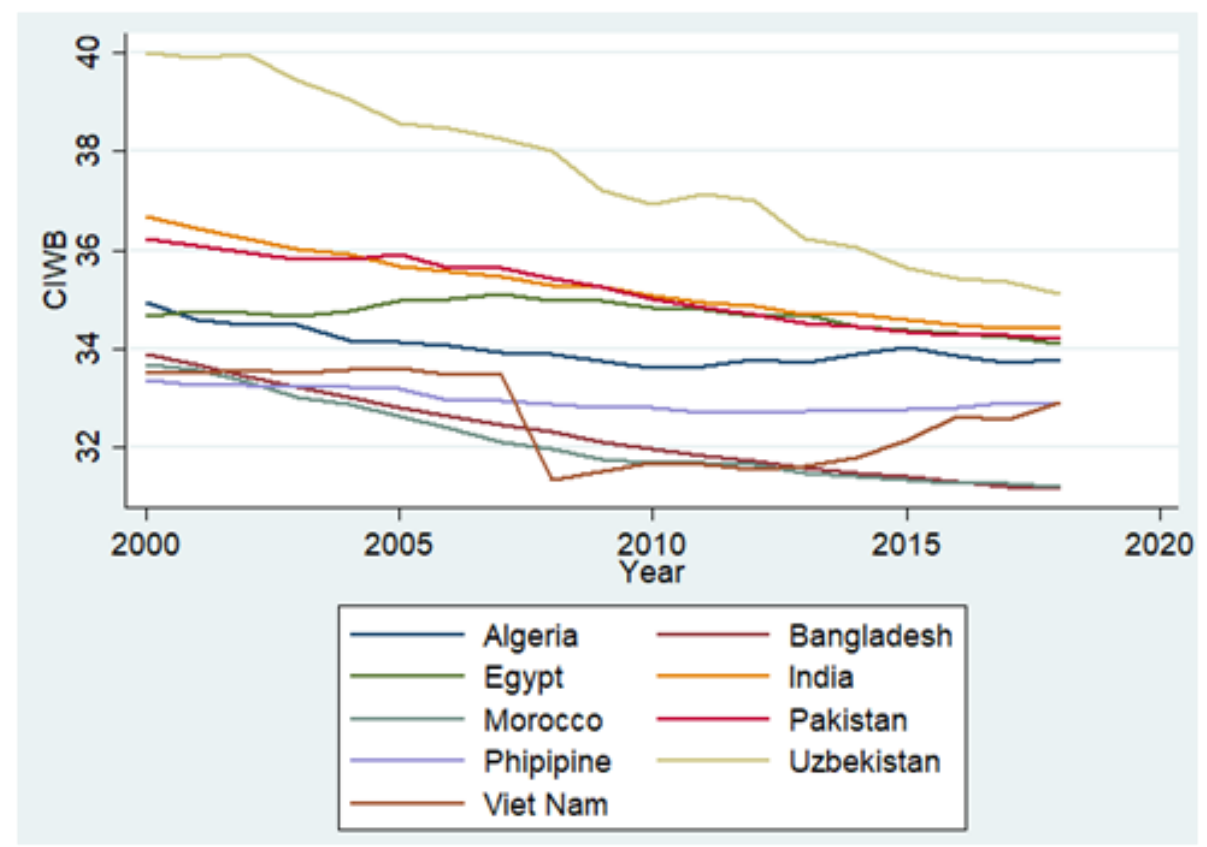

Figure 1. Carbon intensity of well-being (CIWB) in countries

As for the $\mathrm{CIWB}_{\text {it }}$ ratio, our data shows that the coefficient of variation of $\mathrm{CO} 2$ is 0.64 and ranges from0.2-5.04. Meanwhile, the coefficient of variation of life expectancy (LE) is 0.049 and the range is 62.5-76.69. The coefficient of variation of $\mathrm{CO} 2$ (the numerator) is much larger than that of the lifetime (denominator), because the coefficient of variation of the numerator affects the variation of this ratio. Therefore, it is necessary to resolve this problem before considering the CIWB ratio as a dependent variable. We did the same as Dietz, Rosa, and York (2012) and Jorgenson (2014) did a treatment. That is to add a constant to the numerator. The constant value calculated from our sample data was 21.98 and added to the value of CO2. So the adjusted CIWB can be calculated: CIWB $=((\mathrm{CO} 2+21.98) / \mathrm{LE}) * 100$. The values of CIWB of countries after adjustment in Figure 1.

Table 2 reports the findings for the estimated model. The R-squared estimate value is 0.99 significantly high and it indicates that the model can account for $99 \%$ of all CIWB variation. Such unusually high R-squared values are mainly the result of year-specific and country-specific intercepts which are known as fixed effects. Put simply, the R-squared is very 
high due to the use of the two-way fixed effect. The Rho value is within the acceptable statistical range that $87 \%$ of the CIWB variance is explained by country specific disturbances $\left(u_{i}\right)$. This implies that the estimation model, after adjusting for AR (1), has no problem with autocorrelation. Besides, we also checked and did not detect the case of multicollinearity due to adding more dummy variables to the model. In addition, in order to decide if fixed time effects (the period specific intercepts) are needed while running the model, we perform a joint test to check whether the dummy variables for all years are equal to zero. The results show that the null hypothesis that "all years coefficients are jointly equal to zero" is rejected. This fact shows that the period-specific intercepts are significant in the four estimated models.

\section{Table 2}

The effect of energy consumption per capita (dependent variable is CIWB)

\begin{tabular}{|c|c|c|c|}
\hline Independent variables & Coefficients & $\begin{array}{c}\text { Panel corrected } \\
\text { standards errors }\end{array}$ & $\mathbf{P}>|\mathbf{z}|$ \\
\hline ECP & .2505281 & .0102557 & 0.000 \\
ECP_2001 & .0029104 & .0044939 & 0.517 \\
ECP_2002 & .0105277 & .0061022 & 0.084 \\
ECP_2003 & .0172942 & .0076821 & 0.024 \\
ECP_2004 & .0055789 & .0083684 & 0.505 \\
ECP_2005 & -.0003515 & .0093793 & 0.970 \\
ECP_2006 & .0278119 & .0112643 & 0.014 \\
ECP_2007 & .010079 & .0118724 & 0.396 \\
ECP_2008 & .0487246 & .0126368 & 0.000 \\
ECP_2009 & .0216888 & .0133822 & 0.105 \\
ECP_2010 & .0276134 & .0142494 & 0.053 \\
ECP_2011 & .0383506 & .0143938 & 0.008 \\
ECP_2012 & .043654 & .015168 & 0.004 \\
ECP_2013 & .0216207 & .0163952 & 0.187 \\
ECP_2014 & .0130358 & .0170706 & 0.445 \\
ECP_2015 & .0155259 & .0203723 & 0.446 \\
ECP_2016 & .0323442 & .0234627 & 0.168 \\
ECP_2017 & .0280184 & .0256274 & 0.274 \\
ECP_2018 & .0122181 & .0275986 & 0.658 \\
GDP & -.6424431 & .0691638 & 0.000 \\
FDI & -.0023558 & .0010593 & 0.026 \\
Rho & 0.87 & & \\
R-squared & 0.99 & & \\
N & 171 & & \\
\hline
\end{tabular}

Source: The reseacher's data analysis

The results from the regression show the effect of per capita energy consumption in the reference year $2000(0.25)$ and the interaction of per capita energy consumption and the yearly dummy variables $(2002,2003,2006,2008,2010,2011$ and 2012) were positive and statistically significant. In the remaining years, this interaction is mostly positive but not statistically significant. Thus, the relationship between CIWB and energy consumption in these countries is positive and appears to vary in magnitude through time. According to Jorgenson and Clark (2012); Dietz et al. (2012); Knight and Rosa (2011); Grossman and Krueger (1995) argue that the effect of economic performance activity on the environment may change over time. To put it 
more simply, the energy consumption in low-income countries in the middle-income group is creating negative pressure on the environment and changing its magnitude over time.

To understand the impact of energy consumption on the CIWB, Figure 2 will plot and report the coefficients to estimate the influence of energy consumption over the years. The first co-efficient (0.25) plotted and presented in Figure 2 is the impact of energy consumption on CIWB in 2000 and remained constant through 2001. In 2002 and 2003, the estimated coefficients increased by respectively (0.26 and 0.267) and returned to 0.25 in 2004 and 2005 . During the period from 2006-2011, the estimated coefficient of energy consumption fluctuated strongly and tended to increase in absolute value at a higher level than in the period from 20002005. However, in 2005 the estimated coefficient decreased to 0.254 and decreased to 0.25 in 2013 and unchanged until 2018.

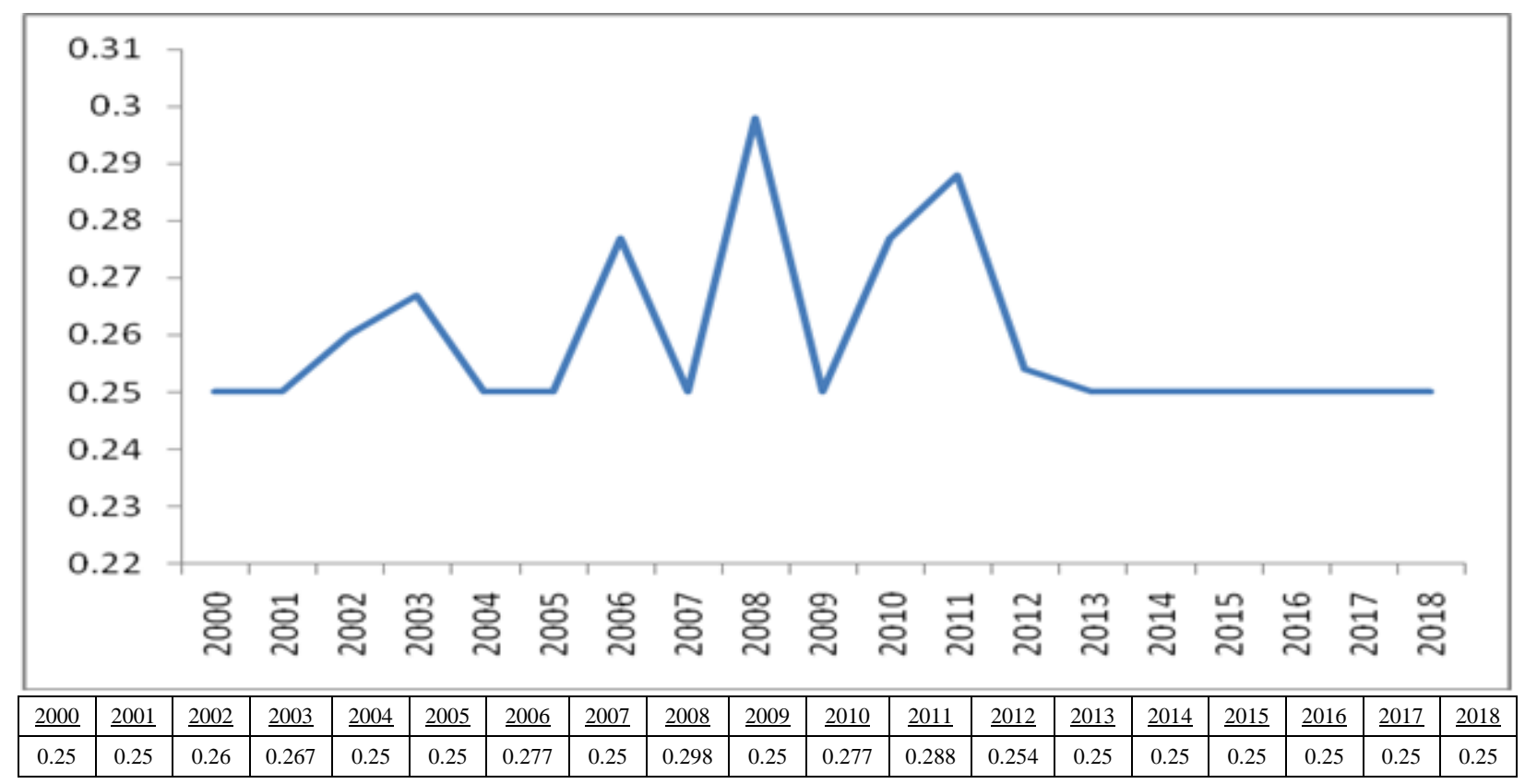

Figure 2. Estimated coefficients of the effect of yearly energy consumption on CIWB

Regarding the control variables GDP per capita and FDI per capita, there are CIWB positive effects and statistically significant. Therefore, these two variables contribute to reducing the stresses on the environment by increasing human well-being.

In summary, our regression results provide a fairly clear picture of the relationship between energy consumption and CIWB in the low-income group of middle-income countries. We come to two main findings:

The relationship between energy consumption and CIWB becomes less sustainable. In other words, the results indicate that energy consumption creates more stress on the environment.

In contrast, GDP per capita and FDI per capita have reduced the pressures exerted on the environment by increasing human well-being.

\section{Conclusions and policy implications}

The environmental effects of human well-being are seen as a branch of sustainable economics. The relationship between economic activity and the environment has attracted the attention of scientists for a long time and is divided into two branches: First, the impact of economic development or economic activities on the environment. And the second, the study of how economic growth can increase human well-being while reducing the pressure on the 
environment. The studies on carbon intensity on well-being (CIWB) is in the second line of sustainable development research. Recently, this direction has attained more interest because almost all countries in the world have prolonged development of economics based on energy consumption and our world is highly threatened by climate change.

In order to have a good understanding of the second line of sustainable development, this study investigates the relationship on CIWB with economic growth by choosing energy consumption as the dependent variable and economic factors like GDP and FDI per capita to be control variables. The data of 9 lower middle - income countries have been selected during 20002018 because they have a significant change in policies toward sustainable development under the Kyoto protocol since 1997.

This study reveals the positive effect of energy consumption on CIWB, which means the more energy consumes, the more CIWB increases. That indicates the economic development based on energy consumption is ineffective on both environment and human well-being. In the other hand, the control variables as GDP and FDI per capita have a negatively significant association with CIWB, thus, economic growth and attracting FDI have increased human well-being.

The study contributes to the academic research on sustainable development by showing that the withdraw of economic success of those lower middle - income countries when based on energy consumption to develop, because of the decline of environment and human well-being. Moreover, it also indicates the possible contribution of economic factors as GDP and FDI per capita to sustainable development. From the results above, the paper offers the following suggestions:

Firstly, the use of energy for economic development is ineffective and inconsistent with the view of sustainable development. Therefore, it is necessary to issue additional policies to limit undesirable outcomes from energy consumption. Besides that, the governments of these countries can implement various policies to promote renewable energy technologies such as capital subsidies, feed in tariffs, tradable certificates, and renewable portfolio standards.

Secondly, policies for economic development and FDI attraction are consistent with the perspective of sustainable development. However, the impact coefficient of FDI is still relatively low. Therefore, it is necessary to apply strict policies for attracting green FDI which reduces stress on the environment in the long term.

\section{References}

Adewuyi, A. O., \& Awodumi, O. B. (2017). Renewable and non-renewable energy-growthemissions linkages: Review of emerging trends with policy implications. Renewable and Sustainable Energy Reviews, 69, 275-291. doi:10.1016/j.rser.2016.11.178

Alkhathlan, K., \& Javid, M. (2015). Carbon emissions and oil consumption in Saudi Arabia. Renewable and Sustainable Energy Reviews, 48, 105-111. doi:10.1016/j.rser.2015.03.072

Allison, P. D. (2009). Fixed effects regression models. Thousand Oaks, CA: SAGE Publications, Inc.

Ang, J. B. (2007). CO2 emissions, energy consumption, and output in France. Energy Policy, 35(10), 4772-4778. doi:10.1016/j.enpol.2007.03.032

Ang, J. B. (2008). Economic development, pollutant emissions and energy consumption in Malaysia. Journal of Policy Modeling, 30(2), 271-278. doi:10.1016/j.jpolmod.2007.04.010

Apergis, N., \& Payne, J. E. (2009). Energy consumption and economic growth in Central America: Evidence from a panel cointegration and error correction model. Energy Economics, 31(2), 211-216. doi:10.1016/j.eneco.2008.09.002 
Baumgartner, S., \& Quaas, M. (2010a). Sustainability economics - General versus specific, and conceptual versus practical. Ecological Economics, 69(11), 2056-2059. doi:10.1016/j.ecolecon.2010.06.018

Baumgartner, S., \& Quaas, M. (2010b). What is sustainability economics? Ecological Economics, 69(3), 445-450. doi:10.1016/j.ecolecon.2009.11.019

Beck, N., \& Katz, J. N. (1995). What to do (and not to do) with time-series cross-section data. The American Political Science Review, 89(3), 634-647. doi:10.2307/2082979

Becker, C. (2012). Sustainability ethics and sustainability research. Cham, Switzerland: Springer.

Bretschger, L., \& Smulders, S. (2007). Sustainable resource use and economic dynamics. Environmental and Resource Economics, 36(1), 1-13. doi:10.1007/s10640-006-9043-x

Cameron, A. C., \& Trivedi, P. K. (2010). Microeconometrics using stata. College Station, TX: Stata Press.

Chen, P.-Y., Chen, S.-T., Hsu, C.-S., \& Chen, C.-C. (2016). Modeling the global relationships among economic growth, energy consumption and $\mathrm{CO} 2$ emissions. Renewable and Sustainable Energy Reviews, 65, 420-431. doi:10.1016/j.rser.2016.06.074

Cowan, W. N., Chang, T., Inglesi-Lotz, R., \& Gupta, R. (2014). The nexus of electricity consumption, economic growth and $\mathrm{CO} 2$ emissions in the BRICS countries. Energy Policy, 66, 359-368. doi:10.1016/j.enpol.2013.10.081

Dietz, T., Rosa, E. A., \& York, R. (2012). Environmentally efficient well-being: Is there a Kuznets curve? Applied Geography, 32(1), 21-28. doi:10.1016/j.apgeog.2010.10.011

Dogan, E., \& Aslan, A. (2017). Exploring the relationship among CO2 emissions, real GDP, energy consumption and tourism in the EU and candidate countries: Evidence from panel models robust to heterogeneity and cross-sectional dependence. Renewable and Sustainable Energy Reviews, 77, 239-245. doi:10.1016/j.rser.2017.03.111

Gould, K. A., Pellow, D. N., \& Schnaiberg, A. (2004). Interrogating the treadmill of production: Everything you wanted to know about the treadmill but were afraid to ask. Organization \& Environment, 17(3), 296-316. doi:10.1177/1086026604268747

Grossman, G. M., \& Krueger, A. B. (1995). Economic growth and the environment. The Quarterly Journal of Economics, 110(2), 353-377. doi:10.2307/2118443

Halicioglu, F. (2009). An econometric study of CO2 emissions, energy consumption, income and foreign trade in Turkey. Energy Policy, 37(3), 1156-1164. doi:10.1016/j.enpol.2008.11.012

Jorgenson, A. K. (2014). Economic development and the carbon intensity of human well-being. Nature Climate Change, 4(3), 186-189. doi:10.1038/nclimate2110

Jorgenson, A. K., \& Clark, B. (2009). The economy, military, and ecologically unequal exchange relationships in comparative perspective: A panel study of the ecological footprints of nations. Social Problems, 56(4), 1975-2000. doi:10.1525/sp.2009.56.4.621

Jorgenson, A. K., \& Clark, B. (2012). Are the economy and the environment decoupling? A comparative international study, 1960-2005. American Journal of Sociology, 118(1), 1-44. doi:10.1086/665990

Jorgenson, A. K., \& Givens, J. (2015). The changing effect of economic development on the consumption-based carbon intensity of well-being. PLoS ONE, 10(5), 1990-2008. doi:10.1371/journal.pone.0123920 
Kanjilal, K., \& Ghosh, S. (2013). Environmental Kuznet's curve for India: Evidence from tests for cointegration with unknown structuralbreaks. Energy Policy, 56, 509-515. doi:10.1016/j.enpol.2013.01.015

Kline, R. B. (2015). Principles and practice of structural equation modeling (4th ed.). New York, NY: The Guilford Press.

Knight, K. W., \& Rosa, E. A. (2011). The environmental efficiency of well-being: A cross-national analysis. Social Science Research, 40(3), 931-949. doi:10.1016/j.ssresearch.2010.11.002

Lewis, T. L. (2019). Globalizing the treadmill of production: A solutions-oriented application to Ecuador. Environmental Sociology, 5(3), 219-231. doi:10.1080/23251042.2018.1514942

Martínez, D. M., \& Ebenhack, B. W. (2008). Understanding the role of energy consumption in human development through the use of saturation phenomena. Energy Policy, 36(4), 14301435. doi:10.1016/j.enpol.2007.12.016

Mazur, A., \& Rosa, E. (1974). Energy and life-style. Science, 186(4164), 607-610.

Narayan, P. K., \& Narayan, S. (2010). Carbon dioxide emissions and economic growth: Panel data evidence from developing countries. Energy Policy, 38(1), 661-666. doi:10.1016/j.enpol.2009.09.005

Pasternak, A. D. (2001). Global energy futures and human development: A framework for analysis. Paper presented at the Global 2001 International Conference on: "Back-end of The Fuel Cycle" From Research To Solutions, Paris, France.

Saboori, B., \& Sulaiman, J. (2013). CO2 emissions, energy consumption and economic growth in Association of Southeast Asian Nations (ASEAN) countries: A cointegration approach. Energy, 55, 813-822. doi:10.1016/j.energy.2013.04.038

Saidi, K., \& Mbarek, M. B. (2016). Nuclear energy, renewable energy, CO2 emissions, and economic growth for nine developed countries: Evidence from panel Granger causality tests. Progress in Nuclear Energy, 88, 364-374. doi:10.1016/j.pnucene.2016.01.018

Schnaiberg, A. (1980). The environment: From surplus to scarcity. New York, NY: Oxford University Press.

Schnaiberg, A., \& Gould, K. (1994). Environment and society: The enduring conflict. New York, NY: St. Martin's Press.

Shahbaz, M., Lean, H. H., \& Shabbir, M. S. (2012). Environmental Kuznets curve hypothesis in Pakistan: Cointegration and granger causality. Renewable and Sustainable Energy Reviews, 16(5), 2947-2953. doi:10.1016/j.rser.2012.02.015

Suarez, C. E. (1995). Energy needs for sustainable human development. In J. Goldemberg \& T. B. Johansson (Eds.), Energy as an instrument for socio-economic development. United Nations Development Programme. New York, NY: UNDP.

Tiba, S., \& Omri, A. (2017). Literature survey on the relationships between energy, environment and economic growth. Renewable and Sustainable Energy Reviews, 69, 1129-1146. doi:10.1016/j.rser.2016.09.113

Zhang, X.-P., \& Cheng, X.-M. (2009). Energy consumption, carbon emissions, and economic growth in China. Ecological Economics, 68(10), 2706-2712. doi:10.1016/j.ecolecon.2009.05.011 